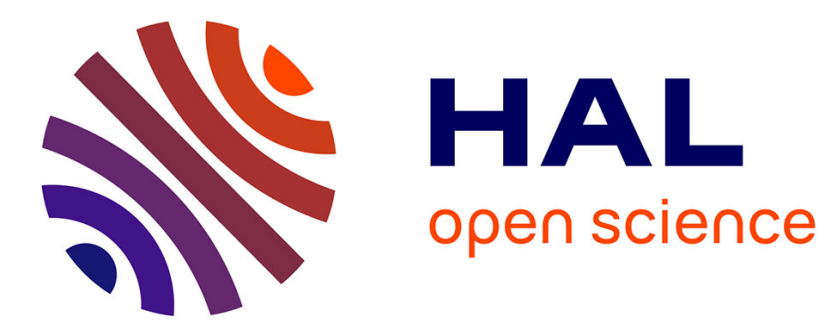

\title{
Lifestyle and awareness of cholesterol blood levels among 29159 community school children in Italy
}

Francesco Martino, Eliana Martino, Paolo Versacci, Tarcisio Niglio, Cristina Zanoni, Paolo E. Puddu

\section{- To cite this version:}

Francesco Martino, Eliana Martino, Paolo Versacci, Tarcisio Niglio, Cristina Zanoni, et al.. Lifestyle and awareness of cholesterol blood levels among 29159 community school children in Italy. Nutrition, Metabolism and Cardiovascular Diseases, 2019, 29, pp.802 - 807. 10.1016/j.numecd.2019.05.060 . hal-03487956

\section{HAL Id: hal-03487956 https://hal.science/hal-03487956}

Submitted on 20 Dec 2021

HAL is a multi-disciplinary open access archive for the deposit and dissemination of scientific research documents, whether they are published or not. The documents may come from teaching and research institutions in France or abroad, or from public or private research centers.
L'archive ouverte pluridisciplinaire HAL, est destinée au dépôt et à la diffusion de documents scientifiques de niveau recherche, publiés ou non, émanant des établissements d'enseignement et de recherche français ou étrangers, des laboratoires publics ou privés.

\section{(ㄷ)(1) $\$$}

Distributed under a Creative Commons Attribution - NonCommerciall 4.0 International 


\title{
Lifestyle and awareness of cholesterol blood levels among 29159 community school children in Italy
}

\author{
Francesco Martino ${ }^{(a)}$, Eliana Martino ${ }^{(a)}$, Paolo Versacci ${ }^{(a)}$, \\ Tarcisio Niglio $^{(\mathrm{b})}$, Cristina Zanoni ${ }^{(\mathrm{a})}$, Paolo Emilio Puddu ${ }^{(\mathrm{c}, \mathrm{d}, \mathrm{e})}$
}

a) Sapienza University of Rome, Department of Pediatrics Gynecology and Obstetrics, 00161 Rome, Italy

b) Istituto Superiore di Sanità Presidenza - Servizio CCS, Viale Regina Elena 299, 00161 Rome, Italy

c) Sapienza University of Rome Department of Cardiovascular, Respiratory, Nephrological, Anesthesiologic and Geriatric Sciences, 00161 Rome, Italy

d) EA 4650, Signalisation, électrophysiologie et imagerie des lésions d'ischémie reperfusion myocardique, UNICAEN, 14000 Caen, France

e) Association for Cardiac Research, 00198 Rome, Italy

Short title: Lifestyle and cholesterolemia awareness among 29159 school children

Words: Title 14, Abstract: 258; Text 2819

Tables 2

References 43 (1314 words)

Author for correspondence and reprints: P.E. Puddu, MD, PhD, FESC, FACC, Sapienza University of Rome, Department of Cardiovascular, Respiratory, Nephrological, Anesthesiological and Geriatric Sciences, Viale del Policlinico, 155, Roma 00161, Italy. Tel. +39.06.49972659; Fax. +39.06.4453891; e-mail: puddu.pe@ gmail.com 


\section{ABSTRACT}

Lifestyle habits including indoor and outdoor activities among community school children, adherence to the Mediterranean diet and awareness about total cholesterol blood levels represent determinant factors in cardiovascular disease (CVD) prevention. The aim of this study was to analyze the relationship between adherence to the Mediterranean diet, total cholesterol blood levels, body composition and hours per day spent in in-house or outdoor among 29159 Italian 6-14 years-old community school children (50\% boys). The KidMed questionnaire, modified to handle missing information on olive oil consumption, was used to assess the adherence to the Mediterranean diet among participants.

Associations between variables were tested according to 3 classes of the Mediterranean diet adherence score using analysis of variance. Participants with high adherence to Mediterranean diet were few (1\%). Overall awareness of total cholesterol blood levels was low among children (4.5\%), slightly higher among parents (26.2 and $24.1 \%$ in mothers and fathers, respectively). Among Mediterranean diet adherent children, BMI was significantly $(\mathrm{p}<0.001)$ smaller than among the non-Mediterranean or intermediate adherent children as were the total hours spent per day watching television or playing with videogames $(p<0.001)$ whereas the hours/day in sport or outdoor activities were more $(\mathrm{p}<0.001)$. These results were confirmed by multiple linear regression with KidMed scored 0 to 8 as dependent variable.

Although awareness of total cholesterol blood levels and adherence to the Mediterranean diet are rare among community school children, only among these a healthier lifestyle was practiced with a tendency to lower CVD risks. These results are important as the first sized experience of this type in Italy.

Key-words: Mediterranean diet adherence; Children; Total cholesterol; KidMed score; Outdoor activities; watching television 


\section{INTRODUCTION}

Although the treatment of cardiovascular disease (CVD) has increased significantly in the last two decades, CVD remains the main cause of morbidity, disability and mortality in Western societies (1). In Europe CVD causes 1.2 million deaths/year whereas in Italy it produces $33.7 \%$ of deaths among men and $41.2 \%$ among women (2). CVD risk factors involved may be disclosed since childhood, sometimes from gestational age and atherosclerotic lesions may appear early, even in adolescent age. The clustering of CVD risk factors in young people is known to be associated with accelerated atherogenesis as well as to an increased risk of chronic diseases such as type 2 diabetes mellitus (T2DM), hypertension and metabolic syndrome in adulthood (3-7). Dyslipidemia and the higher LDL-cholesterol seem to be the most important factors while risk reduction during childhood in the form of primary prevention, including early diagnosis and risk factors' management, can delay the progression to clinical disease $(8,9)$. In fact, endothelial activation is already present in children with hypercholesterolemia $(10,11)$ who have an early increase of oxidative stress responsible for up-regulation of $\mathrm{CD} 40 \mathrm{~L}$, a predisposing factor to premature development of atherosclerosis $(12,13)$.

A correlation between lifestyle and CVD risk factors was reported from the Muscatine and Bogalusa Heart Studies whereby a tracking of total cholesterol blood levels from the pediatric age to that of the adults was clearly observed $(3,14)$. Longitudinal studies also indicated that screen time, gestational weight gain and times per week of vegetable 
consumption may be direct risk factors for the increasing incidence of overweight, obesity and CVD among children and adolescents $(15,16)$. There is an apparent importance of healthier lifestyle habits including physical activity and adherence to the Mediterranean diet also among children and adolescents (17). Regular and constant physical activity, to be interpreted as "education to non-sedentariness" rather than agonistic or non-competitive sport practice, is a major preventive measure for CVD. It mitigates the increase of arterial stiffness that occurs with age $(18,19)$ while improving arterial elasticity if started in the young age. In fact, aerobic exercise programs reduce arterial pressure and stiffness and abdominal fat while increasing cardiorespiratory fitness in obese prepubertal children (20). For favoring and encouraging physical activity in children and adolescents the sensitization and involvement of the family and institutions may be essential (21).

The aim of this study was to evaluate retrospectively, for the first time in Italy among a large population of children in a community school, the correlation between lifestyle and the presence of CVD risk factors, especially of total cholesterol blood levels and body mass index (BMI).

\section{METHODS}

Children aged 6 to 14 years attending primary and secondary schools in the district of Rome were enrolled. They received a family medical history questionnaire at school that was filled-up by their parents at home. Participation was almost $100 \%$. Fourteen children with 
incomplete questionnaire data on dietary habits were excluded from the analysis. Written consent was given by parents directly to school secretaries and kept on records. The Study Protocol was approved locally by the Council of each School and regionally by the Regional Institute for Research and Experimentation for Education, today called IRRE (Istituto Regionale Ricerca e Sperimentazione per l'Educazione, Rome, Italy), the last one acting as an Ethical Committee.

Lifestyle: eating habits, physical activity and sedentary activities. The questionnaire had the following questions: a) number of meals eaten by the subject during the day; b) kind of meals usually taken during the day; c) number of weekly portions consumed at lunch and dinner for: flour and grains, animal meat (cattle, sheep, pig or poultry), fish (fresh or sea water), foods made with fresh vegetables eaten raw, cooked vegetables, legumes, eggs, milk and dairy products, cheese of any kind, fruit, pastries; d) number of weekly portions consumed at breakfast and/or snacks for: pizza, sandwiches, packaged snacks, home baked cakes , chocolate, yogurt, crackers, cookies of all types, fresh fruit, chips, popcorn, fruit juices, sodas.

Parents were asked to indicate the weekly and/or daily frequency of any extracurricular activity such as 1) organized sports activity carried out in the a) indoor facilities; b) outdoor facilities; c) in the pool; 2) autonomous sports activity carried out in outdoor facilities; 3) time spent: a) watching television; b) using a personal computer; c) playing video games; d) reading books; e) in school activities and to study. Parents indicated hours spent in these 
activities. The questionnaire also aimed at having knowledge on the total cholesterol blood levels of the children and their families, including a first relative (brother/sister) of the child and on the familiarity for chronic-degenerative diseases in adulthood (CVD including heart attack, stroke, diabetes, hypertension, tumors). These blood levels were reported from recent Laboratory determinations that were later checked for consistency. During a visit at school weight and height were measured and BMI was derived by standard formulae;

Evaluation of adherence to the Mediterranean diet. The KidMed-test was considered by adapting (17) the 13 questions related to Mediterranean diet compliance to the local conditions and habits whereby certain elements were missing such as exact awareness about olive oil consumption (22). An arithmetic 10-item score ranging from 0 to 8 was thus created to integrate the nutritional information at hand. The following items were coded, based on frequencies or weekly consumptions: 1) a fruit or a commercial fruit juice each day +1 ; 2) a second fruit each day +1 ; 3 ) raw or cooked vegetables once a day +1 ; 4) fish regularly (at least 2-3 times a week) +1 ; 5) legumes(beans, chickpeas, lentils, etc.) at least once a week +1 ; 6) pasta or rice almost each day (at least $\geq 5$ times a week) $+1 ; 7$ ) dairy products (yogurt, milk at breakfast only, etc.) +1 ; 8) yogurts and/or cheese twice daily +1 ; 9) sweets and candies several times each day -1 ; 10) meat twice a week or more -1 . As it is standard in questionnaires of this type frequencies were reported rather than portions. An absolute arithmetic sum of the above scores totalling 0-2 was considered as adherent to a non- 
Mediterranean diet; that scored 3-5 was classified adherent to an Intermediate diet whereas adherence to a Mediterranean diet was scored 6-8.

Statistical analysis. Data were presented by mean \pm standard error (SE) or deviation (SD), where appropriate. Analysis of variance was used to test significance among the 3 categories distributed in their effective numerical sizes variable-wise. Multivariate analysis was performed by multiple linear regression. Several models were run with Kid-Med test as dependent variable either in 3 classes or scored continuously (namely 9 scores from 0 to 8 ). In each model there were 5 dependent variables (age, gender, BMI, hours spent watching television and hours in outdoor sports). Separately, models were also run adding total cholesterol levels to the models with 5-dependent variables. Regression and standardized linear coefficients were computed and T-statistics was used for evaluating statistical significance. NCSS software was used [Hintze, J. (2013). NCSS 9. NCSS, LLC. Kaysville, Utah, USA. www.ncss.com]. A p value $<0.05$ was considered significant.

\section{RESULTS}

There were 29159 children enrolled in the study and the overall results are reported in Table 1. Adherence to the Mediterranean diet was extremely low (1\%) in this entire compulsory and community school cohort, the large majority $(61 \%)$ resulting non-adherent to the Mediterranean diet based on our modified KidMed score. Similarly, total cholesterol blood levels were known among only $4.5 \%$ of the children whereas a bigger proportion of 
parents knew about their cholesterol levels (26.2 and $24.1 \%$ in mothers and fathers, respectively). However, there were no univariate statistical differences in the distributions of total cholesterol blood levels in children, brothers/sisters or parents, based on the Mediterranean diet scores. Yet, non-adherents were significantly older, more frequently female but without any difference from the remaining 2 classes for familiar CVD prevalence.

Referring to Table 1, the most striking differences among the Mediterranean diet score categories were seen for BMI (inverse relation with the presence of Mediterranean diet, $\mathrm{p}<0.001)$ and lifestyle habits (inverse relation for the time spent watching television, playing with videogames and the presence of Mediterranean diet whereas the relation was direct with the time spent in sport or outdoor activities, all $\mathrm{p}<0.001)$ whose results were obtained in the large majority of the enrolled cohort individuals. Interestingly, among Mediterranean diet adherent children, BMI was significantly smaller than among the non-Mediterranean or intermediate adherent children as were the total hours spent per day watching television or playing with videogames whereas the hours/day in sport or outdoor activities were more. On the other hand, relatively inconsistent results were seen for the use of a computer and the hours/day spent to study, both higher among Intermediate diet scored children.

There were 6954 children with missing variables for the 5 dependent covariates entered in the multiple linear regression models and 28100 children having missing variables in the models containing 6 dependent covariates. When the dependent variable was more dispersed (scored from 0 to 8 ) there was expectedly a higher statistical significance in the multivariate 
results as compared to when it was grouped in 3 categories (detailed results not shown). The former results are presented in Table 2 and indicate that a highly significant direct multivariate relation exists between the Kid-Med test scored from 0 to 8 and respectively male gender and the number of hours spent in outdoor sports whereas the relation is inverse with age, BMI and the number of hours spent to watch television.

Among 1059 of 29159 children (3.6\%) with 6 potential predictors, Kid-Med score was significantly and inversely related only to cholesterol levels (standardized coefficient $=-0.066$, $\mathrm{t}=-2.14, \mathrm{p}=0.032$ ) whereas the other 5 independent covariates were not significantly associated although the algebraic signs of the respective standardized coefficients were the same as those significantly seen in Table 2.

\section{DISCUSSION}

The present study showed that adherence to the Mediterranean diet among compulsory community school children was very low (1\%). However, by univariate analysis (Table 1) there was an association between adherence to the Mediterranean diet and BMI and total cholesterol blood levels which was significant for the former and a tendency for the latter. Interestingly, there were statistically significant inverse associations with hours/day spent in sport or outdoor activities among children adherent to the Mediterranean diet whereas the reverse was true for in-house activities such as watching television or playing with videogames that were higher. 
We used a modified KidMed score to handle the missing information on olive oil consumption $(17,22)$ and we point that these results are the first sized reported experience in

\section{Italy of this kind.}

We aimed at assessing the awareness of lifestyle and total cholesterol blood levels in a large school population. Previous studies suggested that the parental history of CVD could influence the risk of CVD risk components clustering in their offspring $(23,24)$. It is possible that common genes and the shared lifestyle in a family may contribute to these associations. With this survey we found that only in a small fraction of children $(4.5 \%)$ there is awareness of total cholesterol blood levels which contrasts with more than $1 / 4$ of parents aware of it. The low rates of lipid testing in our study are similar nevertheless to several other studies that have examined lipid testing via phone surveys and record reviews of well-child visits (25). Data from the National Ambulatory Medical Care Survey involving health maintenance visits among patients aged 2-19 years indicated lipid test orders in only 3\% of visits and negligible increase in testing rates in more recent years (2.5\% in 1995 to $3.2 \%$ in 2010$)(26-28)$.

The relationship between dietary factors and coronary heart disease (CHD) has been a major goal of health research since the early 1960s. Keys et al. connected the Mediterranean diet to lower CHD incidence, by observing that the traditional food model among southern European populations was based on the Mediterranean diet (29). The Mediterranean diet, characterized by the use of starches and vegetable foods such as bread, pasta, vegetables, salads, legumes, fruit, olive oil as the main source of fats, a low or moderate amount of dairy 
products, meat, fish and eggs in low or moderate quantity, has favorable effects on hyperlipidemia and other risk factors for CVD. Among other things, antioxidants derived mainly from plant foods and olive oil, such as vitamin $\mathrm{E}$, beta-carotene, vitamin $\mathrm{C}$, flavonoids and other phenolic compounds, seem to play an important role in the reduction of oxidation of low-density lipoproteins and therefore in the prevention of atherosclerosis. The high intake of oleic acid, thanks to the consumption of olive oil, also reduces blood cholesterol levels $(30,31)$.

Nowadays there is little or no adherence to the Mediterranean diet also in the land where it was initially described, as seen in a cross-sectional survey among a younger generation of adolescents in the heart of the Cilento region in Southern Italy (32). Adherence to the Mediterranean diet was appraised according to a 0-10 scale, taking into account also another 9-point study conducted in the Mediterranean area (Spain) by Martinez-Gonzalez at al. (33). Moreover, the IDEFICS (identification and prevention of dietary- and lifestyleinduced health effects in children and infants) Study showed that in Italy only one child in two, in preschool age, follows the Mediterranean diet and that the percentage even decreases in older ages (34). It is possible that our results were in part influenced by the missing information on olive oil. Nevertheless, it is important to point out that comparative investigations of this size are also missing in Italy.

There is evidence that for most individuals, increasing physical activity improves physical fitness, and high levels of both are related to lower rates of morbidity and mortality 
from various causes, including CVD $(35,36)$. In children, the regular practice of moderate to vigorous physical activity affects endothelial function (37). It seems also that the sedentary lifestyle itself increases the risks of prematurely developing atherosclerosis and other diseases (38). One study showed that even healthy and normal weight children who were classified as having low cardiorespiratory fitness had worse metabolic and inflammatory profiles than those with better fitness (39). Longitudinal studies showed that, for obese children, physical training might improve endothelial function regardless of changes in BMI or body weight (4042).

By multivariate regression analysis it is possible to conclude from more than $2 / 3$ of the studied children that adherence to the Mediterranean Diet is related to a lower BMI whereas the activities at home are less, as exemplified by watching the television and those outdoor, in sports, are more. It also of interest that in a fraction of the overall study, where awareness of cholesterol blood levels was present (3.6\% liable for multivariate regression) these levels were significantly inversely related to the KidMed score. As this is an observational investigation we may not derive causative relationships. Nevertheless, we advance that this is a potentially important observation, yet to be received cautiously and in view of further confirmations that these results may well stimulate.

Limitations. The observational nature of this study leads to some limitations. The major one is a selection bias related to the overall low proportion of individuals (both children and parents) in whom cholesterol blood measurements were obtained who might have been 
the most adherent to health recommendations and therefore to healthier life habits, thus influencing the results obtained. There is therefore a need for further large scale prospective investigations among school children although the high costs and organization skills implicated, especially when blood determinations and/or blood pressure measurements are implicated, should not be neglected.

Conclusions. Our data show that cardiovascular risk factors in children are not adequately evaluated. In addition, total cholesterol blood levels are not frequently considered. However, among children adherent to the Mediterranean diet, there is a greater awareness of the levels of total blood cholesterol that are known more frequently among children and parents (Table 1) and of healthy lifestyle condensed in more hours spent in outdoor sport activities that are in turn related directly to KidMed score as shown multivariately. Most probably, parents influence their children with their educational behavior and awareness of the problem. We noted that the adherence to the Mediterranean diet as indexed by the KidMed score was associated with larger sports' practice, with a lower BMI and with a tendency to have lower total cholesterol blood levels also measured more often. A recent investigation among 387 Icelandic adolescents of 13-16-years old (54\% boys) concluded that a high and medium adherence to Mediterranean diet, scored similar to the present investigation, was associated with high and very high endurance in both girls and boys (43). Thus, although awareness of total cholesterol blood levels and adherence to the Mediterranean diet are rare in the present study (4.5 and 1\%, respectively), it is only among those children 
that a healthier lifestyle is practiced with a tendency to lower CVD risks. These results are important as this is the first sized experience of this type in Italy.

\section{Competing interests}

The authors have declared that no competing interests exist. 


\section{REFERENCES}

1 Roth GA, Johnson C, Abajobir A, et al. Global, regional, and national burden of cardiovascular diseases for 10 causes, 1990 to 2015. J Am Coll Cardiol 2017; 70: 1-25.

2 Townsend N, Nichols M, Scarborough P, Rayner M. Cardiovascular disease in Europeepidemiological update 2015. Eur Heart J 2015; 36: 2696-2705.

3 Berenson GS, Srinivasan SR, Bao W, Newman WP,et al. Association between multiple cardiovascular risk factors and atherosclerosis disease in children and young adults. The Bogalusa Heart Study. N Engl J Med 1998; 338: 1650-1656.

4 Morrison JA, Friedman LA, Gray-McGuire C. Metabolic syndrome in childhood predicts adult cardiovascular disease 25 years later: the Princeton lipid Research Clinics Follow-Up Study. Pediatrics 2007; 120: 340-345.

5 Strong JP, Malcom GT, McMahan CA, et al. Prevalence and extent of atherosclerosis in adolescents. and young adults: implications for prevention from the Pathobiological Determinants of Atherosclerosis in Youth Study. JAMA 1999; 281: 727-735.

6 McMahan CA, Gidding SS, Viikari JSA, et al. Association of pathobiologic determinants of atherosclerosis in youth risk score and 15-year change in risk score with carotid artery intima-media thickness in young adults (from the Cardiovascular Risk in Young Finns Study). Am J Cardiol 2007; 100: 1124-1129.

7 Sommer A, Twig G. The impact of childhood and adolescent obesity on cardiovascular risk in adulthood: a systematic review. Curr Diab Rep 2018; 18: 91.

8 National Heart, Lung, and Blood Institute. Expert panel on integrated guidelines for cardiovascular health and risk reduction in children and adolescents: summary report. Pediatrics Dec 2011, 128 (Supplement 5) S213-S256.

9 Berenson GS, Srinivasan SR, Bao W, Newman WP 3rd, et al. Association between multiple cardiovascular risk factors and atherosclerosis in children and young adults. The Bogalusa Heart Study. N Engl J Med 1998; 338: 1650-1656.

10 Loffredo L, Pignatelli P, Martino F,et al. Early increase of NOX2 derived oxidative stress in children: relationship with age. Pediatric Research 2013; 73: 788-793.

11 Loffredo L, Martino F, Carnevale R, et al. Obesity and Hypercholesterolemia are associated with NOX2 generated oxidative stress and arterial dysfunction. J Pediatr 2012; 161: 1004-1009.

12 Martino F, Pignatelli P, Martino E, et al. Early increase of oxidative stress and soluble CD40L in children with hypercholesterolemia. J Am Coll Cardiol 2007; 49: 1974-1981. 
13 Martino F, Loffredo L, Carnevale R, et al. Oxidative stress is associated with arterial dysfunction and enhanced intima-media thickness in children with hypercholesterolemia: potential role of nicotinamide-adenine dinucleotide phosphate oxidase. Pediatrics 2008; 122: e648-e655.

14 Lauer RM, Clarke WR. Use of cholesterol measurements in childhood for the prediction of adult hypercholesterolemia. The Muscatine Study. JAMA 1999; 264: 3034-3038.

15 Sridhar SB, Darbinian J, Ehrlich SF, et al. Maternal gestational weight gain and offspring risk for childhood overweight or obesity. Am J Obstet Gynecol 2014; 211: 259.e1-8.

16 Buil-Cosiales P, Toledo E, Salas-Salvadó J, et al. Association between dietary fibre intake and fruit, vegetable or whole-grain consumption and the risk of CVD: results from the PREvención con DIeta MEDiterránea (PREDIMED) trial. Br J Nutr 2016; 116: 534-546.

17 Martino F, Puddu PE, Lamacchia F, et al. Mediterranean diet and physical activity impact on the later development of metabolic syndrome among children and adolescents from Southern Italy: Contribution from the Calabrian Sierras Community Study (CSCS). Int J Cardiol 2016; 225: 284-288.

18 Collings PJ, Westgate K, Väistö J, et al. Cross-sectional associations of objectivelymeasured physical activity and sedentary time with body composition and cardiorespiratory fitness in mid-childhood: The PANIC Study. Sports Med 2017; 47: 769-780.

19 Boreham CA, Ferreira I, Twisk JW, et al. Cardiorespiratory fitness, physical activity, and arterial stiffness: the Northern Ireland Young Hearts Project. Hypertension 2004; 44: 721-726.

20 Farpour-Lambert NJ, Aggoun Y, Marchand LM, et al. Physical activity reduces systemic blood pressure and improves early markers of atherosclerosis in prepubertal obese children. J Am Coll Cardiol 2009; 54: 2396-2406.

21 Holm K, Wyatt H, Murphy J, et al. Parental influence on child change in physical activity during a family-based intervention for child weight gain prevention. J Phys Act Health 2012; 9: 661-669.

22 García Cabrera S, Herrera Fernández N, Rodríguez Hernández C, et al. KIDMED test. Prevalence of low adherence to the Mediterranean diet in children and young; a systematic review. Nutr Hosp 2015; 32: 2390-2399.

23 Lee CY, Lin WT, Tsai S, et al. Association of parental overweight and cardiometabolic diseases and pediatric adiposity and lifestyle factors with cardiovascular risk factor clustering in adolescents. Nutrients 2016; 8: E567.

24 Peterson MD, Liu D, Iglay Reger HB, et al. Principal component analysis reveals gender-specific predictors of cardiometabolic risk in 6th graders. Cardiovasc Diabetol 2012; 11: 146. 
25 Kimm, SY, Payne GH, Stylianou MP, et al. National trends in the management of cardiovascular disease risk factors in children: second NHLBI survey of primary care physicians. Pediatrics 1998; 102: E50.

26 Valle CW, Binns HJ, Quadri-Sheriff M, et al. Physicians' lack of adherence to National Heart, Lung, and Blood Institute guidelines for pediatric lipid screening. Clin Pediatr (Phila) 2015; 54: 1200-1205.

27 Vinci SR, Rifas-Shiman SL, Cheng JK, et al. Cholesterol testing among children and adolescents during health visits. JAMA 2014; 311: 1804-1807.

28 Wilson DP, Davis S, Matches S, et al. Universal cholesterol screening of children in community-based amb ulatory pediatric clinics. J Clin Lipidol 2015; 9 (5 suppl.): S88S92.

29 Keys A, Aravanis C, Blackburn H, et al. A multivariate analysis of death and coronary heart disease. Harvard University Press. Cambridge Mass, 1980; pp. 1-381.

30 Menotti A, Puddu PE. How the Seven Countries Study contributed to the definition and development of the Mediterranean diet concept: A 50-year journey. Nutr Metab Cardiovasc Dis 2015; 25: 245-252.

31 Menotti A, Puddu PE. Can we still learn from the Seven Countries Study? Curr Opinion Lipidol 2018; 29: 313-317.

32 Saulle R, Del Prete G, Stelmach-Mardas M, et al. A breaking down of the Mediterranean diet in the land where it was discovered. A cross sectional survey among the young generation of adolescents in the heart of Cilento, Southern Italy. Ann Ig 2016; 28: 349-359.

33 Martínez-González MA, García-López M, Bes-Rastrollo M, et al. Mediterranean diet and the incidence of cardiovascular disease: a Spanish cohort. Nutr Metab Cardiovasc Dis 2011; 21: 237-244.

34 González-Gil EM, Santabárbara J, Russo P, et al. Food intake and inflammation in European children: the IDEFICS study. Eur J Nutr 2015; 55: 2459-2468.

35 Hurtig-Wennolof A, Ruiz JR, Harro M, et al. Cardiorespiratory fitness relates more strongly than physical activity to cardiovascular disease risk factors in healthy children and adolescents: the European Youth Heart Study. Eur J Cardiovasc Prev Rehabil 2007; 14: 575-581.

36 Hainer V, Toplak H, Stich V. Fat or fit: what is more important? Diabetes Care 2009; 32 Suppl 2: S392-S397.

37 Ascenso A, Palmeira A, Pedro LM, et al. Physical activity and cardiorespiratory fitness, but not sedentary behavior, are associated with carotid intima-media thickness in obese adolescents. Eur J Pediatr 2016; 175: 391-398. 
38 Froberg K, Andersen LB. Mini review: physical activity and fitness and its relations to cardiovascular disease risk factors in children. Int J Obes (Lond) 2005; 29 Suppl 2: S3439.

39 Llorente-Cantarero FJ, Pérez-Navero JL, de Dios Benitez-Sillero J. Non-traditional markers of metabolic risk in prepubertal children with different levels of cardiorespiratory fitness. Public Health Nutr 2012; 15: 1827-1834.

40 Bell LM, Watts K, Siafarikas A, et al. Exercise alone reduces insulin resistance in obese children independently of changes in body composition. J Clin Endocrinol Metab 2007; 92: 4230-4235.

41 García-Hermoso A, Correa-Bautista JE, Olloquequi J, et al. Health-related physical fitness and weight status in 13- to 15-year-old Latino adolescents. A pooled analysis. J Pediatr (Rio J) 2018 May 5. doi: 10.1016/j.jped.2018.04.002.

42 Short KR, Pratt LV, Teague AM. A single exercise session increases insulin sensitivity in normal weight and overweight/obese adolescents. Pediatr Diabetes 2018 Apr 23. doi: 10.1111/pedi.12684.

43 Galan-Lopez P, Ries F, Gisladottir T, et al. Healthy Lifestyle: Relationship between Mediterranean diet, body composition and physical fitness in 13 to 16-years old Icelandic students. Int J Environ Res Public Health 2018;15. doi: 10.3390/ijerph15122632. 
Table 1. Overall results grouped by KidMed Score among 29159 compulsory school children.

\begin{tabular}{|c|c|c|c|c|c|}
\hline & \multicolumn{3}{|c|}{ Mediterranean Diet } & \multirow[b]{2}{*}{$\mathrm{F}$} & \multirow[b]{2}{*}{$\mathrm{p}<$} \\
\hline & $\begin{array}{c}\text { No }(\mathbf{0 - 2}) \\
{[\mathrm{N}=17663,61 \%]}\end{array}$ & $\begin{array}{c}\text { Intermediate (3-5) } \\
{[\mathrm{N}=11170,38 \%]}\end{array}$ & $\begin{array}{c}\text { Yes (6-8) } \\
{[\mathrm{N}=326,1 \%]}\end{array}$ & & \\
\hline Age (years) & $9.95 \pm 0.02$ & $9.85 \pm 0.02$ & $9.75 \pm 0.12$ & 7.67 & 0.001 \\
\hline Gender $($ female $=0 ;$ male $=1$ ) & 0.49 & 0.51 & 0.50 & 6.13 & 0.02 \\
\hline \multirow[t]{2}{*}{ Total cholesterol (mg/dl) } & $170 \pm 2$ & $167 \pm 2$ & $153 \pm 12$ & 1.16 & 0.31 \\
\hline & {$[769,4.4 \%]$} & {$[518,4.6 \%]$} & {$[22,6.7 \%]$} & & \\
\hline \multicolumn{2}{|c|}{ Total cholesterol of brother/sister (mg/dl) $163 \pm 2$ [579] } & $158 \pm 2[433]$ & $148 \pm 10[19]$ & 1.93 & 0.14 \\
\hline Age of mother (years) & $39 \pm 0.03$ & $39 \pm 0.03$ & $39 \pm 0.20$ & 0.30 & 0.73 \\
\hline \multirow[t]{2}{*}{ Total cholesterol of mother $(\mathrm{mg} / \mathrm{dl})$} & $183 \pm 0.64$ & $184 \pm 0.80$ & $178 \pm 4.38$ & 1.03 & 0.36 \\
\hline & {$[4602,26.1 \%]$} & {$[2950,26.4 \%]$} & {$[98,30.1 \%]$} & & \\
\hline Age of father (years) & $42 \pm 0.04$ & $42 \pm 0.05$ & $43 \pm 0.31$ & 0.70 & 0.50 \\
\hline Total cholesterol of father (mg/dl) & $205 \pm 0.85[4195]$ & $205 \pm 1.05[2734]$ & $203 \pm 5.64[96]$ & 0.43 & 0.65 \\
\hline Familial CVD (no=0; yes=1) & 0.45 & 0.41 & 0.40 & 0.45 & 0.63 \\
\hline BMI (units) & $18.48 \pm 0.02[13568]$ & ]18.27 \pm 0.03 [8789] & $18.17 \pm 10.20[255]$ & 11.18 & 0.001 \\
\hline Television (hours/day) & $2.23 \pm 0.01[17607]$ & $2.17 \pm 0.01[11111]$ & $2.01 \pm 0.06[322]$ & 15.57 & 0.001 \\
\hline Videogames (hours/day) & $0.70 \pm 0.01[17025]$ & $0.67 \pm 0.01$ & $0.50 \pm 0.04[316]$ & 15.52 & 0.001 \\
\hline Computer (hours/day) & $0.49 \pm 0.01[17277]$ & $0.53 \pm 0.01$ & $0.51 \pm 0.03[318]$ & 10.86 & 0.001 \\
\hline Study (hours/day) & $2.09 \pm 0.01[14273]$ & $2.16 \pm 0.01$ & $2.10 \pm 0.07[253]$ & 10.93 & 0.001 \\
\hline Sport (hours/day) & $2.26 \pm 0.02$ & $2.43 \pm 0.02$ & $2.58 \pm 0.13$ & 20.24 & 0.001 \\
\hline Outdoor Play (no=0; yes $=1$ ) & 0.72 & 0.75 & 0.81 & 24.53 & 0.001 \\
\hline
\end{tabular}

Mean \pm SE. Effective numerical size is presented in squared parentheses when lower than the actual per category representativeness. 
Table 2. Multiple regression with KidMed score 0-8 as dependent variable among 22205 of 29159 (76\%) compulsory school children.

\begin{tabular}{lccccc}
\hline & Mean \pm SD & Regression & Standardized & & \\
& & coefficient & coefficient & t & p $<$ \\
& & & & & \\
\hline & & & & & \\
Age (years) & $9.96 \pm 2.23$ & -0.021 & -0.035 & -4.85 & 0.001 \\
Gender (female=0; male=1) & 0.50 & 0.071 & 0.026 & 3.95 & 0.001 \\
BMI (units) & $18.39 \pm 3.24$ & -0.013 & -0.032 & -4.55 & 0.001 \\
Television (hours/day) & $2.19 \pm 1.08$ & -0.047 & -0.038 & -5.68 & 0.001 \\
Sport (hours/day) & $2.35 \pm 2.26$ & 0.026 & 0.044 & 6.58 & 0.001 \\
Intercept & - & 2.70 & 0.000 & 45.32 & 0.001 \\
KidMed score (0 to 8) & $2.24 \pm 1.34$ & - & - & - & - \\
& & & & & \\
\hline
\end{tabular}

SD: standard deviation. The estimated equation is: KidMed score $=2.70-0.021 *$ Age $-0.013 * \mathrm{BMI}$ $+0.071 *$ Gender $+0.026 *$ Sport hours $-0.047 *$ Television hours $(\mathrm{F}$ ratio $=30.67, \mathrm{p}<0.001)$. 